\title{
Comparison of the Post-Total Knee Arthroplasty Analgesic Effect of Intraoperative Periarticular Injection of Different Analgesics
}

\author{
Moying Liu1, Dongliang Zhang2 and Baoxin Shi1 \\ 1School of Nursing, Tianjin Medical University, China \\ 2Department of Joint and Sports Medicine, Tianjin People's Hospital, China
}

\begin{abstract}
Objective: To compare post-TKA (total knee arthroplasty) analgesic effect of periarticular injection of different analgesics during surgery.

Study Design: Experimental study.

Place and Duration of Study: Tianjin People's Hospital, from December 2016 to July 2018.

Methodology: Patients undergoing unilateral TKA were randomly divided into Group A and Group B, with 67 patients in each group. In Group A, compound analgesics of ropivacaine, ketorolac, adrenaline, morphine and normal saline were injected periarticularly during surgery. While in Group B, compound analgesics of bupivacaine, methylprednisolone, adrenalin, morphine and normal saline were injected periarticularly during surgery. Visual analogue scale (VAS), range of motion (ROM) of knee joint, and rehabilitation of knee joint of both groups were compared.

Results: VAS scores of Group A at 6-hour, 24-hour, 48-hour and 72-hour after surgery was lower than those of Group B $\left(p=0.046, p<0.001, p<0.001\right.$ and $p<0.001$, respectively). ROM of knee joint of Group $A$ on the $3^{\text {rd }}, 7^{\text {th }}, 10^{\text {th }}$ and $14^{\text {th }}$ day after surgery was superior to that of Group B (all $p<0.001)$. On the 14th day after surgery, excellent and good rate of rehabilitation of knee joint of Group A was higher than that of Group B ( $p=0.032)$.

Conclusion: Compared with periarticular injection of compound analgesics of bupivacaine, methylprednisolone, adrenaline, morphine and normal saline during surgery, periarticular injection of compound analgesics of ropivacaine, ketorolac, adrenaline, morphine and normal saline during surgery can alleviate post-TKA pain more effectively, improve early ROM of joint knee after surgery, increase rehabilitation effect of knee joint.
\end{abstract}

Key Words: Periarticular, Knee, Replacement, Surgery, Analgesics, Pain.

How to cite this article: Liu M, Zhang D, Shi B. Comparison of the post-total knee arthroplasty analgesic effect of intraoperative periarticular injection of different analgesics . J Coll Physicians Surg Pak 2019; 29(12):1169-1172.

\section{INTRODUCTION}

Total knee arthroplasty (TKA) refers to the use of a prosthesis made of artificial material to replace a knee joint, to improve the pain, limited ROM and joint deformity as a result of knee osteoarthritis, rheumatoid arthritis and knee trauma, etc. and reconstruct a joint with almost normal functions, and restore and improve the mobility of joint, ${ }^{1,2}$ thereby improving the patients' quality of life. Pain is the most common early complication following a surgery. The acute pain within $24 \mathrm{~h}$ after surgery can postpone the early rehabilitation training of patients after TKA; and directly affect their functional recovery and surgical effect. ${ }^{3}$ Controlling postoperative pain properly plays a significant role in the post-TKA rehabilitation of patients' knee functions. Although the use of a patient-controlled analgesia (PCA) pump can control postoperative pain to a certain extent, using a

Correspondence to: Dongliang Zhang, Department of Joint and Sports Medicine, Tianjin People's Hospital, China E-mail:lpsjm3@163.com

Received: October 19, 2018; Revised: October 20, 2019; Accepted: November 28, 2019 large dose of morphine can easily lead to urinary retention, respiratory depression and other side effects. ${ }^{4}$ Other analgesic methods, such as continuous epidural block, continuous lumbar plexus block, and continuous femoral nerve block can also control pain and reduce the use of analgesics, but are prone to muscle weakness, neurologic impairment and other complications. 5,6

The periarticular injection of mixed analgesics is a novel method to relieve pain after surgery. Research has shown the intraarticular injection of analgesics during a knee joint surgery can alleviate pain after the surgery effectively. ${ }^{7}$ However, the efficacy of the intraarticular injection of analgesics during TKA remains unclear. Ropivacaine, ketorolac, adrenaline and bupivacaine, etc. are common drugs for local anesthesia. Adolph et al. reported that injecting compound analgesics, such as bupivacaine, morphine and adrenaline into the soft tissues around joints during surgery, can reduce the postoperative VAS score, the demand for morphine and postoperative blood loss. ${ }^{8}$

The objective of this study was to compare the post-TKA analgesic effects of the periarticular injection of compound analgesics of ropivacaine, ketorolac, adrenaline, morphine 
and normal saline during surgery and the periarticular injection of compound analgesics of bupivacaine, methylprednisolone, adrenaline, morphine and normal saline during surgery. ${ }^{9}$

\section{METHODOLOGY}

This study was conducted at Tianjin People's Hospital, from December 2016 to July 2018. It was approved by the Hospital Ethics and Research Committee. A total of 134 patients receiving unilateral TKA at the Hospital from September 2016 to May 2018 were selected. The inclusion criteria were patients who were diagnosed as knee osteoarthritis or rheumatoid arthritis and intended to receive a unilateral TKA; patients with preoperative chronic pain in the unilateral knee joint, accompanied by functional disorder, who did not respond to conservative treatment; whose preoperative ASA grading (the preoperative grading criteria of the American Society of Anesthesiologists) was I-II and who signed informed consent before surgery. The exclusion criteria were patients with bilateral knee joints involvements; a history of drug dependence or allergy to narcotics; a history of stroke or neuropsychiatric disorder; coagulation dysfunction; obvious fixed deformity; communication disorders; and who were allergic to the medicines injected in this study. All the patients were divided into Group A and Group B randomly, with 67 patients in each group, using the random number table.

Both groups received unilateral TKA (all of the surgeries were performed by the same group of surgeons and anesthetists). After the installation of prosthetic limbs, different compound analgesics were injected into the quadriceps femoris device, tenaculum, medial collateral ligament, fat and subcutaneous tissues and infiltrated. Among them, Group A was given $400 \mathrm{mg}$ ropivacaine, $30 \mathrm{mg}$ ketorolac, $0.3 \mathrm{mg}$ adrenaline, $5 \mathrm{mg}$ morphine and normal saline (with a total volume of $40 \mathrm{~mL}$ ). Group B was administered $200 \mathrm{mg}$ bupivacaine, $40 \mathrm{mg}$ methylprednisolone, $0.3 \mathrm{mg}$ adrenaline, $5 \mathrm{mg}$ morphine and normal saline (with a total volume of $40 \mathrm{~mL}$ ). On the other hand, patients in two groups were injected with 75 $\mathrm{mg}$ pethidine intramuscularly $6 \mathrm{~h}$ after surgery. Another injection of $75 \mathrm{mg}$ pethidine would be given at an interval of 6-10h, depending on the degree of pain. The next day $400 \mathrm{mg} / \mathrm{d}$ COX-2 inhibitor (Celecoxib) was administered orally.

Patients in both groups adopted the same rehabilitation training method, that is, to start active dorsiflexion of ankle joint after surgery, and initiate CPM (continuous passive motion) training on the $2^{\text {nd }}$ day after surgery, and they were allowed to use a pair of crutches to bear part of the load.

The pain scores of patients on admission and 6-hour, 24-hour, 48-hour and 72-hour after surgery (in a resting state) were observed and recorded using a visual analogue scale (VAS). The ROM of knee joint of patients on the $3^{\text {rd }}, 7^{\text {th }}, 10^{\text {th }}$ and 14 th day after surgery was monitored, to evaluate the recovery of knee joint. On the 14th day after surgery, the HSS scores of the patients were measured, in order to assess the recovery of knee function. The HSS score was composed of 7 categories, with a total score of 100 points. Among them, 6 categories were addition categories, that is, 30 points for pain, 22 points for function, 18 points for range of motion, 10 points for muscle strength, flexion deformity and instability each. One category was deduction category, which involved crutch use, varus and valgus deformity and extensor lag. Based on these scores, the clinical effects were rated as excellent $(\geq 85)$, good $(70-84)$, medium (60-69) or poor ( $\leq 59)$. The excellent and good rate $=($ excellent + good cases $) /$ total cases $\times 100 \%$. Meanwhile, both groups were compared in terms of the occurrence of postoperative complications.

Data was analysed in SPSS version 21. Mean value \pm SD was calculated for numerical variables like VAS pain score and ROM, examined by independent sample t-test. Frequencies and percentages were calculated for categorical variables like gender, knee rehabilitation. Chi-square test was applied to compare the categorical variables in two groups. Results were considered significant at $p<0.05$.

\section{RESULTS}

Of the 134 patients, $34(25.37 \%)$ patients were males and $100(74.63 \%)$ patients were females, aged $57-73$ $(65.41 \pm 3.25)$ years. TKA operation was performed on the left knee in $64(47.76 \%)$ cases and on the right knee in $70(52.24 \%)$ cases. The body mass index was $21-27$ $(23.86 \pm 1.72) \mathrm{kg} / \mathrm{m}^{2}$. There were $103(76.87 \%)$ cases of osteoarthritis of the knee and $31(23.13 \%)$ cases of rheumatoid arthritis. Preoperative ASA level: 49 $(36.57 \%)$ cases were in level I, $85(63.43 \%)$ cases were in level II.

There was no significant difference between Group A and Group B in terms of the VAS score on admission $(p=0.930)$. The VAS scores of Group A 6-hour, 24-hour, 48-hour and 72-hour after surgery (in a resting state) was lower than those of Group B $(p=0.046, p<0.001$, $p<0.001$ and $p<0.001$, respectively, Table I). The ROM of knee joint of Group A on the $3^{\text {rd }}, 7^{\text {th }}, 10^{\text {th }}$ and $14^{\text {th }}$ day after surgery was superior to that of Group B (all $p<0.001$, Table II).

On the 14th day after surgery, excellent and good rate of the rehabilitation of knee joint of Group A was $91.04 \%$ (61 cases), which was higher than that of Group B at $77.61 \%$ (52 cases) $(p=0.032)$ (Table III).

No wound complication or toxicity in the heart or central nervous system was observed in either group due to the injection of compound analgesics. 
Table I: Comparison between two groups in terms of VAS scores at different time (score)

\begin{tabular}{|c|c|c|c|c|c|c|c|c|c|c|c|}
\hline \multirow[t]{2}{*}{ Groups } & \multirow[t]{2}{*}{$n$} & \multicolumn{2}{|c|}{ On admission } & \multicolumn{2}{|c|}{$\begin{array}{l}\text { At } 6 \mathrm{~h} \text { of } \\
\text { postoperative } \\
\text { resting state }\end{array}$} & \multicolumn{2}{|c|}{$\begin{array}{c}\text { At } 24 \mathrm{~h} \text { of } \\
\text { postoperative } \\
\text { resting state }\end{array}$} & \multicolumn{2}{|c|}{$\begin{array}{l}\text { At } 48 \mathrm{~h} \text { of } \\
\text { postoperative } \\
\text { resting state }\end{array}$} & \multicolumn{2}{|c|}{$\begin{array}{l}\text { At } 72 \mathrm{~h} \text { of } \\
\text { postoperative } \\
\text { resting state }\end{array}$} \\
\hline & & Mean $\pm S D$ & $p$-value & Mean \pm SD & $\mathrm{p}$-value & Mean $\pm S D$ & $p$-value & Mean $\pm S D$ & $p$-value & Mean \pm SD & $\mathrm{p}$-value \\
\hline Group A & 67 & $5.73 \pm 1.28$ & 0.930 & $2.94 \pm 1.06$ & 0.046 & $3.26 \pm 1.07$ & $<0.001$ & $3.73 \pm 0.86$ & $<0.001$ & $3.59 \pm 0.77$ & $<0.001$ \\
\hline Group B & 67 & $5.71 \pm 1.35$ & & $3.34 \pm 1.23$ & & $3.93 \pm 1.02$ & & $4.68 \pm 0.91$ & & $4.42 \pm 0.85$ & \\
\hline
\end{tabular}

Table II: Comparison between two groups in terms of the ROM of knee joint at different time (o).

\begin{tabular}{|c|c|c|c|c|c|c|c|c|c|}
\hline \multirow[t]{2}{*}{ Groups } & \multirow[t]{2}{*}{$\mathrm{n}$} & \multicolumn{2}{|c|}{$\begin{array}{l}\text { On the 3rd day } \\
\text { after surgery }\end{array}$} & \multicolumn{2}{|c|}{$\begin{array}{l}\text { On the } 7 \text { th day } \\
\text { after surgery }\end{array}$} & \multicolumn{2}{|c|}{$\begin{array}{l}\text { On the } 10 \text { th day } \\
\text { after surgery }\end{array}$} & \multicolumn{2}{|c|}{$\begin{array}{l}\text { On the } 14 \text { th day } \\
\text { after surgery }\end{array}$} \\
\hline & & Mean $\pm S D$ & $p$-value & Mean $\pm S D$ & $p$-value & Mean $\pm S D$ & $p$-value & Mean $\pm S D$ & $p$-value \\
\hline Group A & 67 & $43.61 \pm 3.37$ & $<0.001$ & $76.77 \pm 3.12$ & $<0.001$ & $86.32 \pm 4.71$ & $<0.001$ & $90.78 \pm 2.64$ & $<0.001$ \\
\hline Group B & 67 & $37.54 \pm 5.02$ & & $70.39 \pm 3.48$ & & $78.49 \pm 5.57$ & & $84.85 \pm 3.73$ & \\
\hline
\end{tabular}

Table III: Comparison between two groups in terms of the rehabilitation of knee joint on the $14^{\text {th }}$ day after surgery.

\begin{tabular}{l|c|c|c|c|c|c}
\hline Groups & $\mathrm{n}$ & $\begin{array}{c}\text { Excellent } \\
\mathrm{n}(\%)\end{array}$ & $\begin{array}{c}\text { Good } \\
\mathrm{n}(\%)\end{array}$ & $\begin{array}{c}\text { Medium } \\
\mathrm{n}(\%)\end{array}$ & $\begin{array}{c}\text { Poor } \\
\mathrm{n}(\%)\end{array}$ & $\begin{array}{c}\text { Excellent rate } \\
\mathrm{n}(\%)\end{array}$ \\
\hline Group A & 67 & $49(73.13)$ & $12(17.91)$ & $5(7.46)$ & $1(1.49)$ & $61(91.04)$ \\
Group B & 67 & $43(64.18)$ & $9(13.43)$ & $9(13.43)$ & $6(8.96)$ & $52(77.61)$ \\
\hline
\end{tabular}

\section{DISCUSSION}

Some studies found that the intraarticular injection of local anesthetic after TKA could reduce postoperative pain. ${ }^{10}$ Tsukada et al. also confirmed that compared with epidural analgesia, the periarticular injection of local anesthetic had a better postoperative analgesic effect, earlier recovery of the flexion angle of knee, and lower incidence of nausea. ${ }^{11}$ On the other hand, some studies pointed out that injecting local anesthetics into the articular cavity after TKA did not diminish the use of postoperative analgesics. ${ }^{12}$ Ritter et al. argued that patients undergoing TKA and receiving intraarticular injection, who were divided into four groups, i.e., placebo, morphine, bupivacaine and morphine+ bupivacaine, had no difference in the length of stay, the pain score, and the use of analgesics and nonsteroidal anti-inflammatory drugs (NSAIDS) 24 hours after surgery. ${ }^{13}$

At present, the main ingredient of most clinical drugs injected into the soft tissues around the joint is local anesthetics, combined with morphine, hormone and NSAIDS. In this study, both groups use adrenaline and morphine. Adrenaline slows down the absorption of the analgesics by contracting blood vessels, which prolongs the efficacy of drugs while reducing its toxicity, and also diminishes postoperative and intraoperative bleeding. ${ }^{14,15}$ There are abundant opioid receptors in the surrounding inflammatory tissue, the receptors appear shortly after trauma and bind to morphine effectively to reduce pain.16 A randomised double-blind study revealed addition of morphine and ketolorac to ropivacaine intraarticularly enhanced analgesic efficacy of local anesthesia, reduced postdischarge analgesic consumption. ${ }^{17}$

The present study confirms that compared with the intraoperative injection of compound analgesics in Group B, the intraoperative injection of compound analgesics in
Group A can lower the VAS score of patients in a resting state 24 hours after surgery more effectively; and improve the early ROM after surgery. It is suggested that the periarticular injection of compound analgesics of ropivacaine, ketorolac, adrenaline, morphine and normal saline during surgery can better control post-TKA pain and contribute to the rehabilitation of the knee functions of patients. This conclusion is basically consistent with those of other studies. ${ }^{18}$ The possible reasons include: first of all, ropivacaine and bupivacaine are long-acting local anesthetics with similar pharmacokinetics, but ropivacaine has lower toxicity and lasts longer than bupivacaine. So the duration of analgesia in Group A is longer, which is conducive to the functional training of patients after surgery. Secondly, Group A takes ketorolac as NSAID. NSAIDS inhibits the activity of COX-2 through a variety of pathways, including the synthesis of prostaglandin, inhibits lipoxidase pathway, interferes with the signal transduction mediated by G-protein and binds with opioid receptors in order to achieve the effect of analgesia. ${ }^{19}$ Thirdly, ketorolac synergizes with morphine, enhances the analgesic effect and achieves the effect of analgesia. 20

One study reported that COX-2 inhibitor can increase the risk of heart diseases. ${ }^{21}$ Although both groups adopt COX-2 inhibitor (Celecoxib) after surgery, no wound complication or toxicity in the heart or central nervous system is observed in either group due to the injection of compound analgesics. This may be related to the small sample size included in the present study. In view of this, further studies are needed to confirm the exact effect of COX-2 inhibitor on the risk of cardiovascular diseases. The authors intend to increase the sample size and optimise the evaluation indicators, to further support the clinical effect of the periarticular injection of compound analgesics of ropivacaine, ketorolac, adrenaline, morphine and normal saline during TKA. 


\section{CONCLUSION}

Compared with the periarticular injection of compound analgesics of bupivacaine, methylprednisolone, adrenaline, morphine and normal saline during surgery, the periarticular injection of compound analgesics of ropivacaine, ketorolac, adrenaline, morphine and normal saline during surgery can alleviate post-TKA pain more effectively, improve the early ROM of joint knee after surgery, increase the rehabilitation effect of knee joint.

\section{ETHICAL APPROVAL:}

Ethical approval was taken from Ethical Review Commette of Tianjin People's Hospital before beginning of the research work.

\section{PATIENTS' CONSENT:}

Informed consents were obtained from the patients in local language as per ethical guidelines.

\section{CONFLICT OF INTEREST:}

Authors declared no conflict of interest.

\section{AUTHORS' CONTRIBUTION:}

ML: Responsible for the analysis of data for the work.

BS: Responsible for the conception and design of the work.

DZ: Responsible for revising it critically for important intellectual content and for the final approval of the version to be published.

\section{REFERENCES}

1. Hong KH, Pan JK, Xie H, Guo D, Yang WY, Su HT, et al. Review: Autologous blood transfusion drainage compared with no drainage in total knee arthroplasty: A meta-analysis and systematic review. Pak J Pharm Sci 2017; 30:2321-7.

2. Ahmed W, Lakdawala RH, Mohib Y, Qureshi A, Rashid RH. Does obesity affects early infection after total knee arthroplasty. A comparison of obese vs. non-obese patients. J Pak Med Assoc 2016; 66:S96-8.

3. Fajardo M, Collins J, Landa J, Adler E, Meere P, Di Cesare PE. Effect of a perioperative intra-articular injection on pain control and early range of motion following bilateral TKA. Orthopedics 2011; 34:354

4. Yu S, Dundon J, Solovyova O, Bosco J, lorio R. Can multimodal pain management in TKA eliminate patient-controlled analgesia and femoral nerve blocks? Clin Orthop Relat Res 2018; 476:101-9.

5. Fedriani de Matos JJ, Atienza Carrasco FJ, Díaz Crespo J, Moreno Martín A, Tatsidis Tatsidis P, Torres Morera LM. Effectiveness and safety of continuous ultrasound-guided femoral nerve block versus epidural analgesia after total knee arthroplasty. Rev Esp Anestesiol Reanim 2017; 64:79-85.

6. Sultan WA, Ibrahim ES, EI-Tahawy MS. Continuous psoas sciatic blockade for total knee arthroplasty. Saudi J Anaesth 2018; 12:426-32.

7. Elsharnouby NM, Eid HE, Abou Elezz NF, Moharram AN. Intraarticular injection of magnesium sulphate and/or bupivacaine for postoperative analgesia after arthroscopic knee surgery. Anesth Analg 2008; 106:1548-52.

8. Lombardi AV Jr, Berend KR, Mallory TH, Dodds KL, Adams JB. Soft tissue and intra-articular injection of bupivacaine, epinephrine, and morphine has a beneficial effect after total knee arthroplasty. Clin Orthop Relat Res 2004; 428:125-30.

9. Browne C, Copp S, Reden L, Pulido P, Colwell C Jr. Bupivacaine bolus injection versus placebo for pain management following total knee arthroplasty. J Arthroplasty 2004; 19:377-80.

10. Rasmussen S, Kramhøft MU, Sperling KP, Pedersen JH. Increased flexion and reduced hospital stay with continuous intraarticular morphine and ropivacaine after primary total knee replacement: open intervention study of efficacy and safety in 154 patients. Acta Orthop Scand 2004; 75:606-9.

11. Tsukada S, Wakui M, Hoshino A. Postoperative epidural analgesia compared with intraoperative periarticular injection for pain control following total knee arthroplasty under spinal anesthesia: a randomized controlled trial. J Bone Joint Surg Am 2014; 96:1433-8.

12. DeWeese FT, Akbari Z, Carline E. Pain control after knee arthroplasty: Intraarticular versus epidural anesthesia. Clin Orthop Relat Res 2001; 392:226-31.

13. Ritter MA, Koehler M, Keating EM, Faris PM, Meding JB. Intraarticular morphine and/or bupivacaine after total knee replacement. J Bone Joint Surg Br 1999; 81:301-3.

14. Mutlu V, Kaya Z. Comparison of the effect of the lidocaine, tetracaine, and articaine application into nasal packs on pain and hemorrhage after septoplasty. Eur Arch Otorhinolaryngol 2018; 275:2481-5.

15. Tolska HK, Takala AJ, Jero J. Peritonsillar infiltration of lidocaine with adrenaline is associated with increased risk of secondary post-tonsillectomy haemorrhage. J Laryngol Otol 2018:1-12.

16. Harper P, Hald O, Lwaleed BA, Kyyaly A, Johnston D, Cooper AJ, et al. The impact of morphine treatment on bladder cancer cell proliferation and apoptosis: in vitro studies. Exp Oncol 2018; 40:190-3.

17. Ng HP, Nordström U, Axelsson K, Perniola AD, Gustav E, Ryttberg $L$, et al. Efficacy of intra-articular bupivacaine, ropivacaine, or a combination of ropivacaine, morphine, and ketorolac on postoperative pain relief after ambulatory arthroscopic knee surgery: a randomized double-blind study. Reg Anesth Pain Med 2006; 31:26-33.

18. Busch CA, Shore BJ, Bhandari R, Ganapathy S, MacDonald SJ, Bourne RB, Rorabeck CH, McCalden RW. Efficacy of periarticular multimodal drug injection in total knee arthro-plasty. A randomized trial. J Bone Joint Surg Am 2006; 88:959-63.

19. Aranda JV, Salomone F, Valencia GB, Beharry KD. Nonsteroidal anti-inflammatory drugs in newborns and ynfants. Pediatr Clin North Am 2017; 64:1327-40.

20. Gupta A, Axelsson K, Allvin R, Liszka-Hackzell J, Rawal N, Althoff $\mathrm{B}$, et al. Postoperative pain following knee arthroscopy: The effects of intra-articular ketorolac and/or morphine. Reg Anesth Pain Med 1999; 24:225-30.

21. Hersh EV, Lally ET, Moore PA. Update on cyclooxygenase inhibitors: Has a third COX isoform entered the fray? Curr Med Res Opin 2005; 21:1217-26. 